\title{
REVEALING TELEVISION'S ANALOGUE HEROES
}

\author{
Vanessa Jackson \\ School of Media \\ Birmingham City University \\ Parkside Building \\ Birmingham \\ B4 7BD \\ United Kingdom \\ vanessa.jackson@bcu.ac.uk
}

\begin{abstract}
In this article I will argue that we need to create new archival models in order to preserve and share knowledge of historical, 'hidden' television professions and production cultures. Oral history traditions of recording life stories give us a useful starting point. Engineering 'encounters' between skilled television technicians, and the now obsolete equipment they operated in the 1970 s and 80 s, is challenging for a myriad of reasons, but videoing the interaction of man and machine provides us with a rich insight into how analogue television was produced and broadcast. Social media enables us to disseminate these histories in new and innovative ways.
\end{abstract}

Keywords: Television, Online, Archive, Analogue

\section{Introduction}

In this article I will argue that we need to adopt an alternative way of exploring television history, one that focuses on the human histories of television, and particularly the working lives of television professionals. Through this we can create alternative historical records, which complement and supplement traditional archives, and which can reveal to us 'hidden' historical narratives about the culture of TV analogue production.

It can be argued that most roles in television production are 'hidden,' to a greater or lesser extent. Presenters are evidently visible, and it is widely known that there are directors, producers, camera operators, sound recordists, electricians lighting the set, make-up, wardrobe, and design, but there are a myriad of other production team and crew involved, who are less obvious; and even amongst the jobs we are familiar with, we do not necessarily understand fully what a particular role involves.

Television production methods, and the technology involved, have changed markedly since John Logie Baird's early experiments. ${ }^{1}$ In Britain, the industry grew from the live studio and outside broadcast transmissions of the late 1940 s and ' 50 s, to the developments of 2-inch, and then 1-inch videotape, followed by the introduction of portable 
single camera production, and later the move from analogue to digital, and the impact that had, particularly on post production. These changes have been evolutionary and far reaching, with the workforce constantly adapting to updating technologies and production practices. The histories of these production methods are not necessarily widely known, nor well documented in traditional archives. The processes behind how analogue television was made are intricate and illustrate how important and complex the engineering and other technical roles were.

There is a danger that we think we understand how television is made, and do not realize that there are hidden professions, and a heritage to be preserved. With the advent of camcorders, amateur desktop editing and the ubiquity of contemporary 'behind the scenes' programming, we assume we understand the television production process, and therefore do not ask questions about how television was made in the pre-digital age. As the television crew members from the 1960s, '70s and ' 80 s age, and obsolete technology is consigned to the scrapheap, we risk losing the histories of the hidden television professions, if we fail to preserve them now.

The questions that need to be asked include: is there a value in preserving hidden television histories, beyond the sense of merely understanding the chronology of televisual evolution? Is it important to document and share these histories, to unearth the 'hidden professions'? If so, then how best should we record these histories? And how should we disseminate them as widely and accessibly as possible?

\section{The Value of Historical Records}

Scholars like Rachel Moseley and Helen Wheatley have argued that studying television's past has ramifications for the present and future of television archiving, of television scholarship, and, potentially for television itself. ${ }^{2}$ This chimes with Stephen Lacey's view that 'good enough' empirical accounts of the past, allow us to illuminate the present, especially at times of change within the medium. ${ }^{3}$ It would seem that an understanding of past production methods shows us how technology has led developments in broadcasting, and influenced changes in production cultures and shifts in the power relationships within sections of the television professions. Additionally it teaches us a new found respect for the professionalism of the analogue pioneers.

Lynn Spigel sees the creation of legacy television archives as deeply entwined with issues of institutional power. ${ }^{4}$ These traditional institutions, for instance the seemingly comprehensive BBC Written Archives at Caversham, preserve the production files and documentation about how the broadcast centres were equipped, but there is little trace of the production practices, about how particular equipment was operated, or what a new piece of technology allowed you to do in terms of programme making, that its predecessor did not. It is the human interaction that is missing in the archives, which preserve only the tangible, physical artefacts. We need new archival methods to reveal television's hidden human histories.

\footnotetext{
2 Rachel Moseley and Helen Wheatley, 'Is Archiving a Feminist Issue? Historical Research and the Past, Present and Future of Television Studies,' Cinema Journal, 47, 3, 2008 p. 152.

3 Stephen Lacey, 'Some Thoughts on Television History and Historiography: A British Perspective,' Critical Studies in Television, Spring 2006, 1, 1, p.10-11

${ }_{4}^{4}$ Lynn Spigel, Housing Television: Architecture of the Archive, The Communication Review, 13, 1, 2010, p.55.
} 


\section{Approach}

Oral history projects seem ideally suited to recording the life stories of television's less visible professions. A bottomup approach, which includes documenting the working lives of technicians who actually operated the equipment, would seem to supplement the institutional archives, and partially redress the gaps. There are successful examples of such projects in other fields, such as the Oral history of recorded sound, ${ }^{5}$ and Lives in the Oil Industry, ${ }^{6}$ but I would argue that we need to go further than simply recording the life stories: we need to see the crew members actually operating the equipment. Talking about memories of how a piece of technology worked is nothing but a pale imitation of being reunited with a particular machine, and demonstrating how it worked and what it was capable of. Operating the equipment again, stimulates other thoughts and memories about it, as well as provoking other questions from the interviewer, which would not necessarily be triggered by an in-depth interview alone.

Oral historians traditionally record audio material only, and in fact proponents like Paul Thompson consider radio a more suitable medium than video for displaying it. ${ }^{7}$ I disagree with this view, finding audio alone insufficient to document the kind of physical interaction we are talking about here, which needs to seen as well as heard. Filming requires a range of additional skills from the oral historian, and significantly more equipment than auditory recordings, but is essential to preserve meaningful histories of bygone production techniques. Logistically, setting up this kind of encounter is far more challenging than arranging for a life story interview, as tracking down working examples of obsolete machinery, marrying them with skilled technicians, and then getting permission to film the interaction between operator and machine, is no mean feat.

\section{New Archival Models}

Many oral historians see wide dissemination of the resulting recorded interviews as highly desirable. ${ }^{8}$ It is therefore unfortunate that so many oral history collections lie inaccessible; even the British Library collections mentioned earlier - Oral history of recorded sound and Lives in the Oil Industry - are not easily accessible for members of the public. It is to be hoped that new technologies and less defensive access arrangements encourage a wider appreciation of such projects. This is acknowledged by some oral historians who see the potential of digital tools in providing us with new ways of listening to, sharing, and telling life stories. ${ }^{9}$

Archival possibilities are changing with the advent of Web 2.0 technologies. Megan Dougherty and Steven Schneider give us a chronology of archival development: from the static physical institutional archive they call 'Archive 1.0,' built to keep and organise pieces of the past, to the searchable database repositories termed 'Archive 2.0,' where the archivist catalogued artefacts for the benefit of the archive user, to the online digital capabilities of 'Archive 3.0,' with the potential for interactivity and much wider accessibility and enrichment. ${ }^{10}$ 'Archive 3.0 ' takes preservation and accessibility beyond the exclusive domain of the institution. Now anyone with a computer and access to the Internet has the potential to create their own online archive. This has seen the rise of what Dougherty and Schneider call 'the

\footnotetext{
5 Oral history of recorded sound, https://sounds.bl.uk/Oral-history/Oral-history-of-recorded-sound

${ }^{6}$ Lives in the Oil Industry project, 2005, http://www.bl.uk/reshelp/findhelprestype/sound/ohist/ohnls/nlsoil/oil.html

7 Paul Thompson, The Voice of the Past - Oral History. Oxford University Press, Oxford, London, New York, 1978, p. 206.

8 Ibid. See also Siobhan McHugh, 'Oral history and the radio documentary/feature: Introducing the 'COHRD' form,' The Radio Journal International Studies in Broadcast and Audio Media, 2012, p. 38; and Alice Yang Murray, 'Oral History Research, Theory and Asian American Studies', Amerasia Journal, 2000, 26, 1, p. 117.

9 Steven High, Jessica Mills and Stacey Zembrzycki, 'Telling Our Stories/Animating Our Past: A Status Report on Oral History and Digital Media,' Canadian Journal of Communication, 2012, 37, p. 384.

${ }_{10}$ Megan Dougherty and Steven M. Schneider, Web Historiography and the Emergence of New Archival Forms in The Long History of New Media, Technology, Historiography, and Contextualizing Newness, David W. Park, Nicholas W. Jankowski, Steve Jones eds. Peter Laing Publishing, Inc., 2011.
} 
idiosyncratic archive. ${ }^{11}$ Rick Prelinger reminds us that the contemporary archive faces reinvention, and that accepting the existence of new practices may extend, or conversely rebuke legacy practices. ${ }^{12}$ Online archives, particularly those established by enthusiasts, rather than institutions, tend to favour access over preservation. 'Archive 3.0' has had a democratising effect on archiving, allowing ordinary lives to be more readily 'saved' for the future, meaning that we can construct, display and store those stories much more easily..$^{13}$

\section{Case Study: The Pebble Mill Project}

The creation of 'idiosyncratic archives' would seem to offer attractive possibilities for the revealing of hidden histories. In 2010 I set up the Pebble Mill Project, an online resource to document and share the production histories surrounding BBC Pebble Mill: the first purpose built broadcast production centre for television and radio in the world. The broadcast centre was located in Birmingham, UK, opening in 1971, and closing in 2004, with most production moving to a more central location in the city. It was built during a period of expanding television production in the UK English Regions, which coincides quite neatly with John Ellis's notion of 'an era of availability. ${ }^{14}$ At its height Pebble Mill produced around $10 \%$ of BBC television and radio output. ${ }^{15}$ It boasted a renowned drama department, which produced Plays for Today such as: Nuts in May (1976), Gangsters (1975), Penda's Fen (1974), and series like Boys from the Blackstuff (1982), Empire Road (1978-9) and many others. There was also a prolific factual unit which created long running series like Top Gear (1977-present), Countryfile (1988-present) and Gardeners' World (1968-present) and live studio programming, often for daytime television, such as Pebble Mill at One (1972-86), and Good Morning with Anne and Nick (1992-6). Much of Pebble Mill's output falls into Frances Bonner's definition of 'ordinary television': programming, often formatted and factual, incorporating 'real people. ${ }^{16}$ These types of programme are often neglected in terms of scholarship and critical acclaim.

The Pebble Mill Project takes the form of a website, which could be termed an 'idiosyncratic archive'. It contains an eclectic mixture of photographs, videos and written blogs. I try and post material on the website most days. As a former series producer at BBC Pebble Mill, I have access to some artefacts myself, but the vast majority of material is donated to me by former BBC staff members, and it is access to these previous colleagues which makes the website a potentially rich resource. The site has become a community archive, and one where many of the users actively participate.

There was a relatively stable staff at Pebble Mill, working on a range of programming. The staff tended to know each other quite well, and many have stayed in touch since the building closed, remembering their time at Pebble Mill fondly. These people are often happy to share their photographs and memories.

Attached to the website is an ancillary Facebook group, which has around 1200 members, many of whom were employees of Pebble Mill. When I post on the website, I copy the link across to the Facebook group and invite people to comment. People also post their own photographs and memories on the Facebook group, which, with their permission, I then copy across to the website. The relationship between the website and the Facebook group is symbiotic. Facebook drives traffic to the website, and people seem to feel more comfortable commenting on Facebook, rather than the website. The community seems to typify Axel Bruns model of 'produsage', where users actively participate, and 'produce' content for the site, rather than being passive consumers of content. ${ }^{17}$

11 Ibid, p. 259

12 Rick Prelinger, Archives and Access in the 21 $1^{\text {st }}$ Century, Cinema Journal, 46, 3, 2007, p.18.

13 Paul, L. Arthur, Saving Lives: Digital Biography and Life Writing, in Save As Digital Memories, eds, Joanne Garde-Hansen, Andrew Hoskins,

Anna Reading, Palgrave Macmillan, 2009, p. 46.

14 John Ellis, Seeing Things: Television in the Age of Uncertainty, I.B. Tauris \& Co Ltd, London, 2000.

15 John Wood, writing for Prospero, September 2005, available on http://www.pebblemill.org/blog/2005-prospero-article-john-wood/

16 Frances Bonner, Ordinary Television - Analyzing Popular TV, Sage Publications Ltd, London, 2003.

17 Axel Bruns, Blogs, Wikipedia, Second Life, and Beyond: From Production to Produsage, Peter Lang Publishing Inc, New York, 2008, p. 14. 


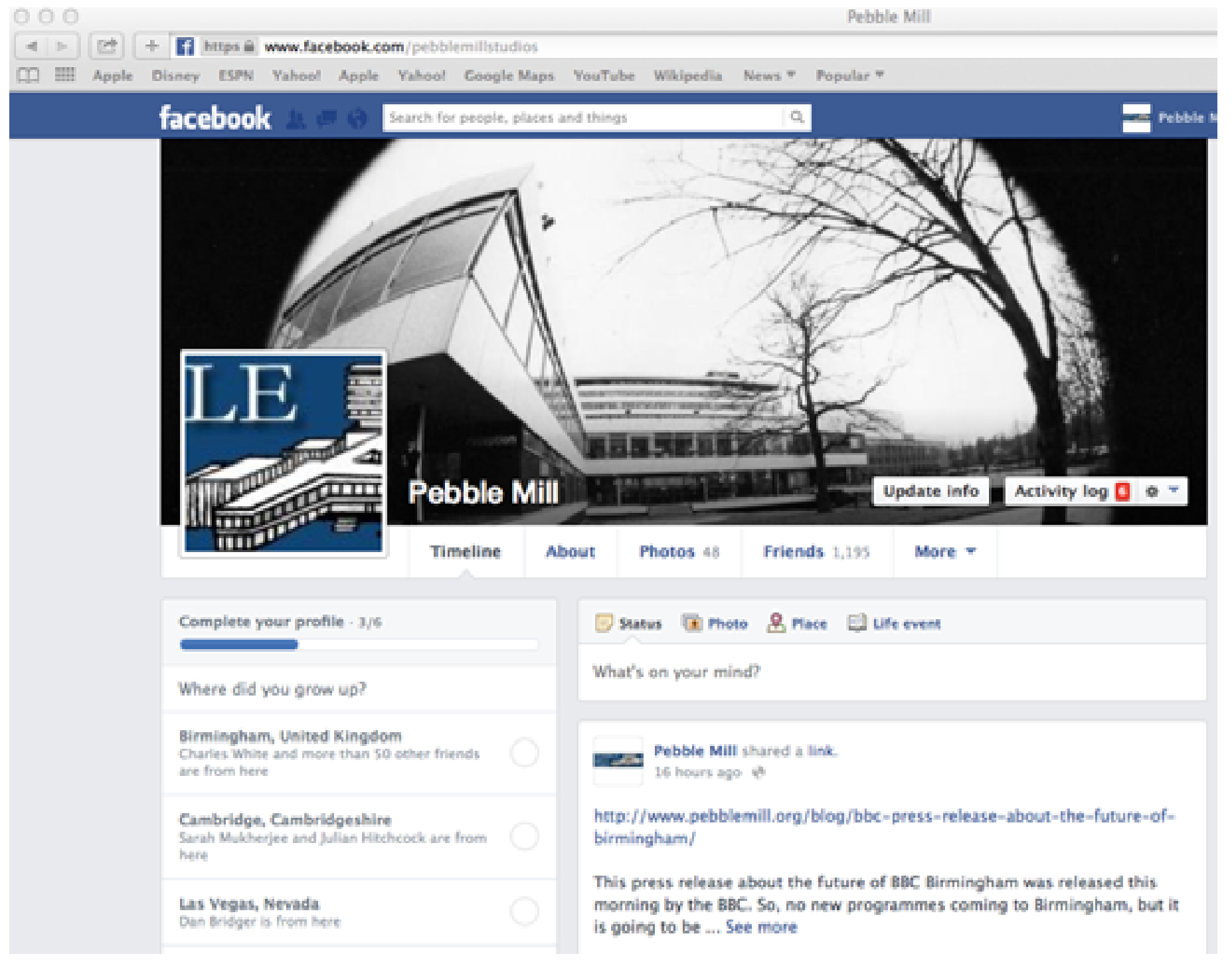

Photo 1: Pebble Mill Facebook group 


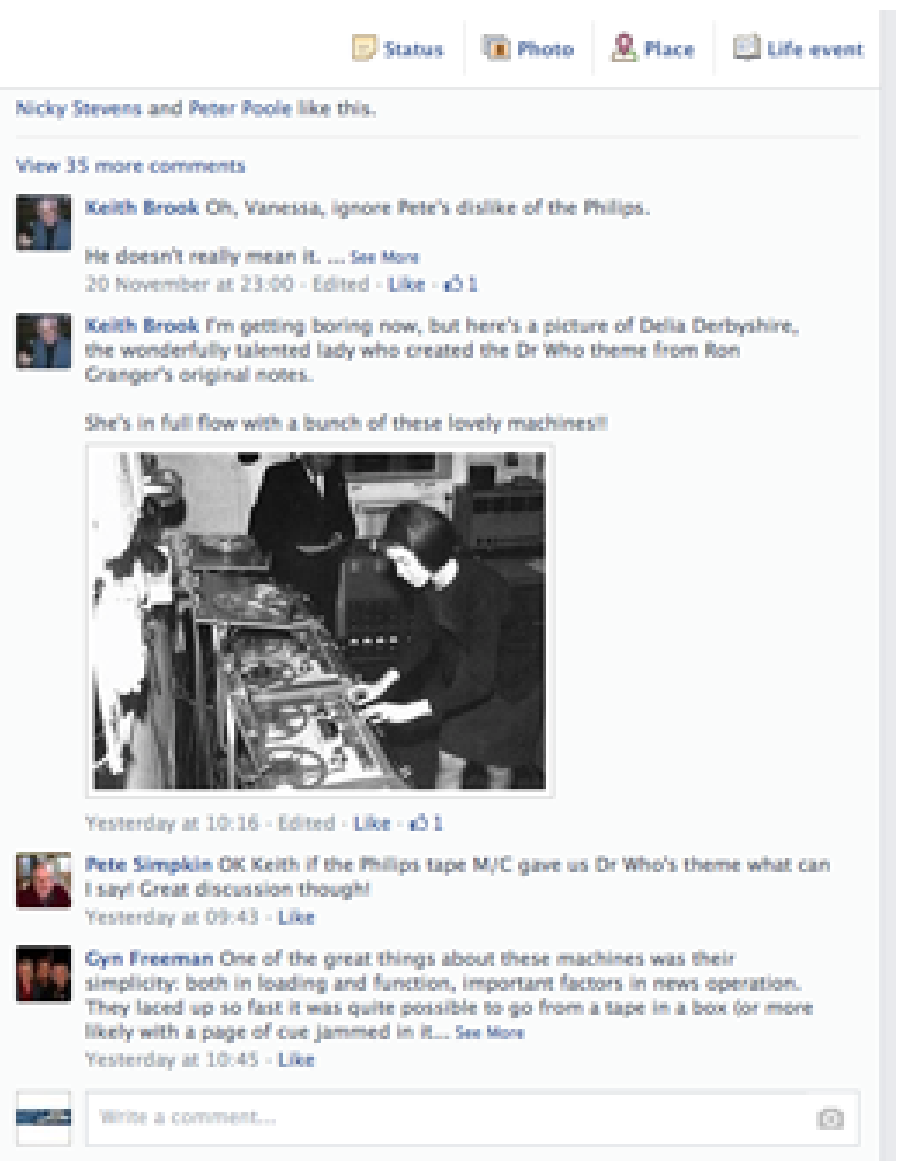

Photo 2: Pebble Mill Facebook interaction

Due to $\mathrm{BBC}$ rights issues, there is no $\mathrm{BBC}$ moving image material on the site. The videos tend to be interviews with programme makers or technical staff, which I have produced specially for the project. I plan to create many more of these videos to document the television production practices of the last quarter of the twentieth century. I am aiming to adopt an oral history approach in producing the videos, although interpreting this in a loose sense, as it is the story of people's working lives that I am particularly interested in, rather than their childhoods and family life. I video the interviews, as I think this provides a more complete record and a more engaging end product for people to watch. I edit the interviews, splitting them up into smaller items, more suitable for viewing online, and include illustrative photographs where possible. The finished videos are uploaded to the Vimeo platform, and then embedded in blog posts on the Pebble Mill website. 


\section{Analogue Outside Broadcast Production}

During the 1970s and 1980s most location based factual, and many drama series were recorded by outside broadcast trucks, known as scanners.

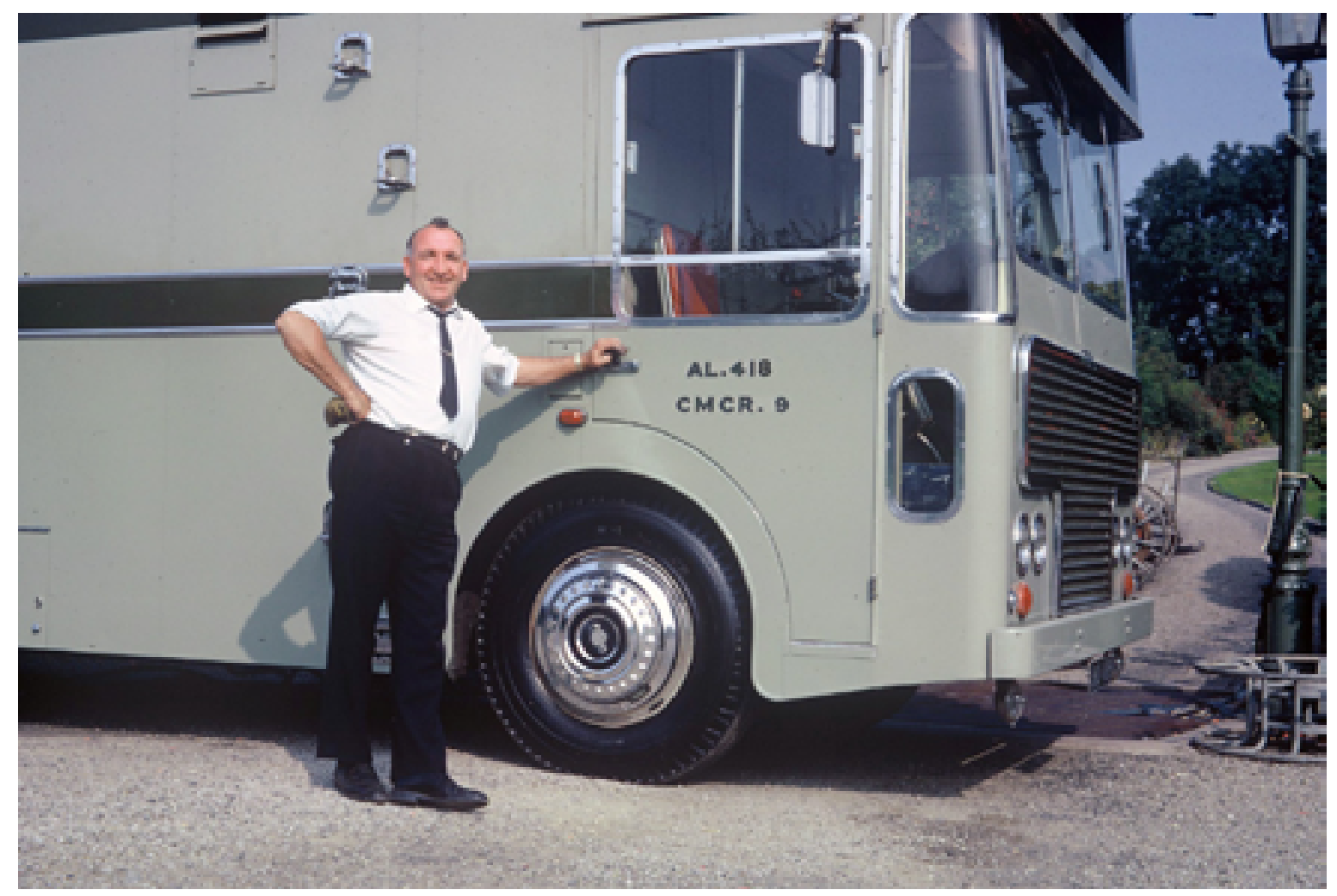

Photo 3: Outside Broadcast Scanner Exterior

They were called 'scanners' because the first outside broadcast van in the early 1930s, built by Baird to cover the Derby horse race to a London cinema, consisted of a huge scanning disk of mirrors, which whirled round and converted the scene into a television signal. The vehicle became known as a 'scanner', and the name stuck, even long after the scanning disk had been replaced. ${ }^{18}$ Scanners in the 1970 s and 80 s usually ran four cameras, sometimes more, which were linked by cable back to the vehicle. The outputs of the cameras were cut between via the vision mixer in the truck and transmitted live or recorded on to either 2-inch or 1-inch videotape. There was the capability to carry out very simple editing, by rewinding the tape to a shot change and picking up the shot again, although this was much more difficult to do with 2-inch videotape, as you could not see pictures when spooling.

BBC programmes made by Pebble Mill staff, like Gardeners' World (1968 onwards), Come Dancing (1949-98), Farming (circa 1960-88), inserts for Pebble Mill at One (1972-86), dramas like Empire Road (1978-9), as well as football and other sports coverage would have all been covered by outside broadcast scanners.

The scanners required a whole host of skilled technicians to operate them, all with very specific jobs to do. There would be up to fifteen people working in the truck during a transmission, with additional riggers, camera operators, boom swingers (operating the microphones), floor managers and assistants, working outside the scanner. 
V. Jackson, Revealing Television's Analogue Heroes

In 1969 the BBC was in the process of moving from black and white to colour technology and commissioned a number of new colour scanners. These were called CMCR (Colour Mobile Control Room) vehicles.

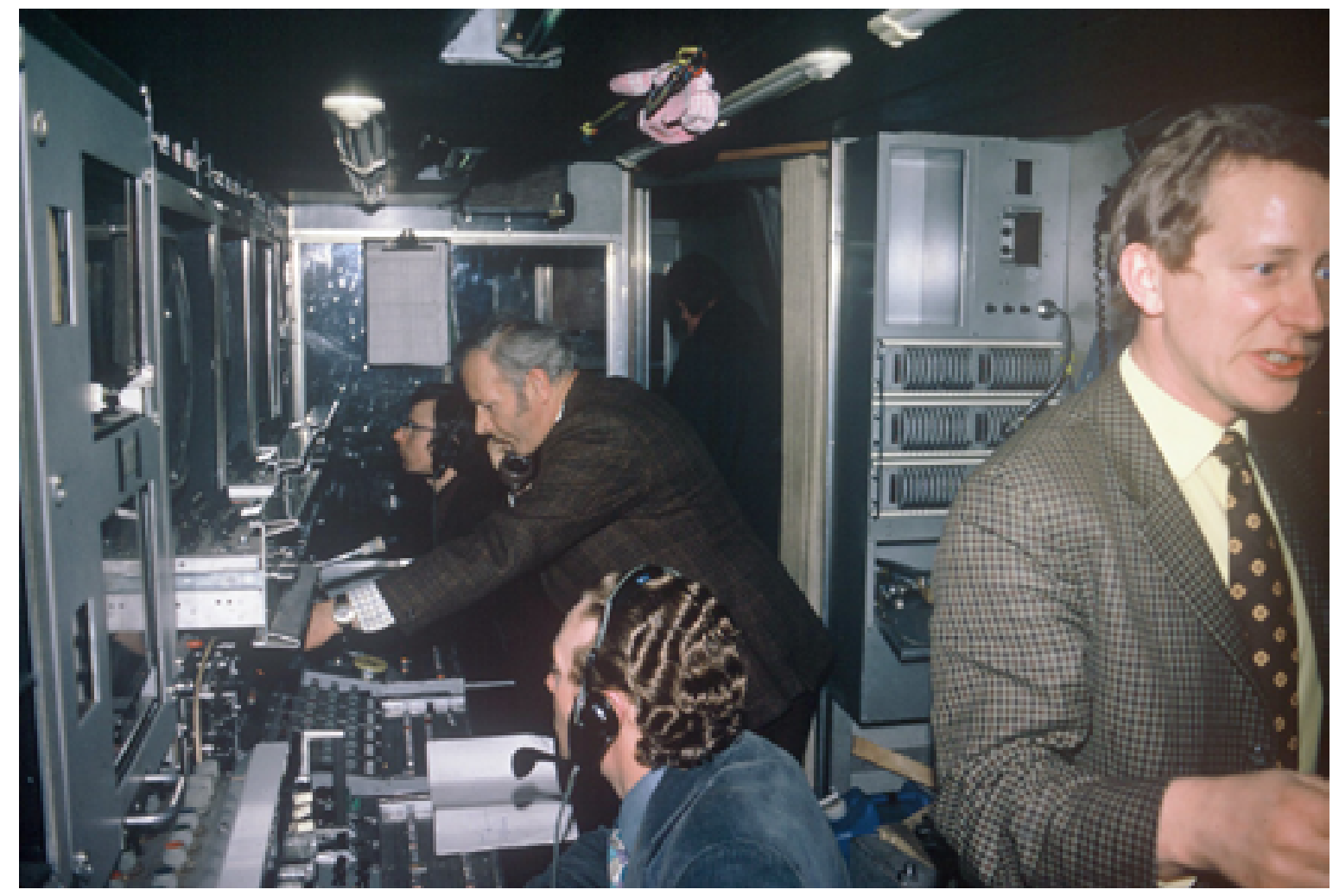

Photo 4: Colour Mobile Control Room Interior

CMCR9 was one of this fleet and originally based in London, it was then reassigned to BBC Pebble Mill in the mid 1970s, and was known as 'CM1' (Colour Midland 1), before being moved to BBC Manchester and becoming 'North 3' from 1980-82. After it was retired from service, the vehicle was sold on several times and slowly deteriorated. It spent at least ten years rusting away in an aircraft hangar. ${ }^{19} \mathrm{~A}$ few years ago CMCR9 was resold to an enthusiast, Steve Harris, a former television lighting director, who was determined to restore the truck, which with the help of a team of dedicated and knowledgeable supporters, he has been able to do. Steve now displays the scanner at various events, around the north of England and the Midlands.

In October 2012 CMCR9 was on display at an exhibition being held at the University of Salford. Since it is difficult to find 'working' examples of television apparatus from the 1970s and ' 80 s, I went along and recorded a couple of videos with technical staff who had worked on the vehicle during its broadcast career (these videos are included later in this article). Whilst the truck has been extensively restored both internally and externally, there is still a lot of work to do, particularly on the electronics such as the camera control units (CCUs). This means that the scanner is not in full working order, and not capable of actually recording a programme, although this is the long-term ambition.

19 Jerry Clegg, 'Down but not out - a vintage scanner rolls again', Prospero, November 2009, http://downloads.bbc.co.uk/mypension/en/ november prospero.pdf 


\section{Discoveries}

\subsection{The Role of the General Post Office (GPO) in Outside Broadcasts}

With each of the videos I recorded came a surprise, with the disclosure by the technician of something about the analogue production process, which I did not know about or had not realised the significance of before. In the first interview, it was the importance of plugging in to the GPO system, which you can see in the video and which I mention later.

I recorded an interview with Jerry Clegg, a retired sound supervisor, who had worked on CMCR9 as a sound assistant. In this video he demonstrates how the vision-mixing desk works, switching between different camera sources, and having the capability to do wipes and effects, as well as cuts and mixes. He also shows how the controls of the sound mixing desk worked, providing operators with many more options for controlling and balancing different sound sources, including being able to adjust low, mid and top end frequencies. Jerry's actual role as a sound assistant on this scanner was to patch in the communications via a system of Post Office jacks and to ensure that everyone involved in the production, both inside the truck, and at outside sources could talk to each other. For example this would enable the director on a sports outside broadcast to be able to talk to the commentators and vice versa.

The video is rather rough around the edges, and the audio quality suffers from not being recorded on a directional microphone. These limitations are due to recording it as a one-person operation and being unable to control the amount of noise happening inside the vehicle. However, the video does serve to illustrate some interesting and potentially significant points. After a gap of thirty years, Jerry is still comfortable operating the equipment on the scanner. He demonstrates a muscle memory for where all the controls are and knows how each piece of the system worked. He adds some surprising information about the vulnerability of the television transmission system: that an audio output which peaked too high, could take out a whole transmitter, knocking the programme off air and meaning the no one in a particular geographical area could receive a BBC signal until the fault was fixed. In terms of revealing a hidden television profession, I had not realised, until I made this video, that a sound assistant would actually be running the communications side of the outside broadcast. I had assumed, wrongly, that the job would involve micing up contributors (attaching personal microphones to interviewees and presenters), and checking the audio feeds back to the truck, and not patching in internal communication channels (connecting the various internal phone lines using Post Office jacks, back at the truck). Without being able to see the jack panel and the communication switches it would be difficult for an outsider to understand the role correctly. Conversely it would be difficult for the interviewee to describe the functionality without having the physical equipment to demonstrate with.

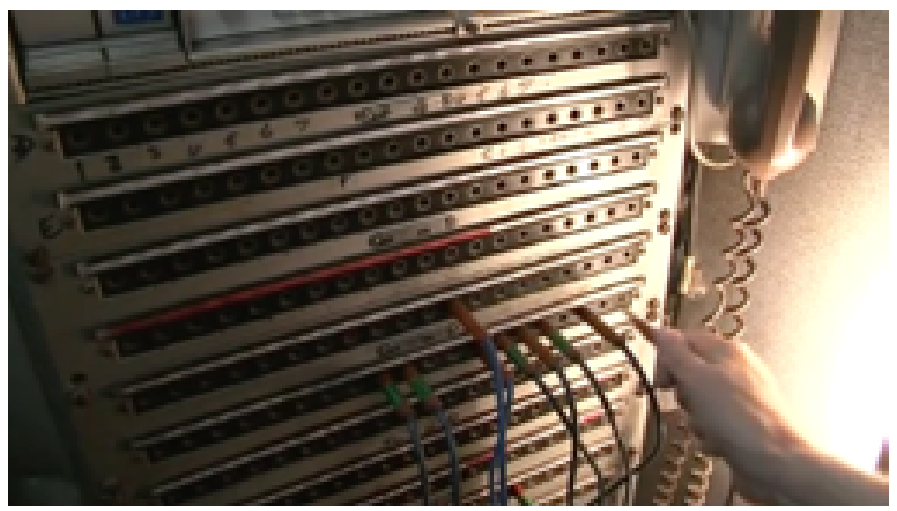




\subsection{How Colour Programmes Were Produced in Black and White Studios}

In the second interview, the discovery was about how colour outside broadcast trucks were used as drive-ins, to convert a black and white studio recording into a colour operation.

CMCR9 was fitted out with Pye PC80 cameras, which was slightly awkward when it was transferred to BBC Pebble Mill, as all the studios there had EMI 2001 cameras, and it was more difficult to maintain two different fleets of studio/ outside broadcast cameras. At some point, either whilst still in Birmingham, or when it had moved to Manchester, the cameras on CMCR9 were changed to the more ubiquitous EMI 2001 camera. The restorers of the scanner have been able to locate a Pye PC80 and an EMI 2001 camera, and these were on display at the University of Salford exhibition. A couple of retired cameramen attended the exhibition and I took the opportunity of asking one of them to demonstrate the cameras to me.

Malcolm Carr handles the cameras with consummate ease. Whilst others at the exhibition were reverential and treated the cameras as if they were museum exhibits, the cameramen who attended were enthusiastic about operating equipment, which was replaced by newer technology around thirty years ago. What surprised me about the content of the encounter is the sophistication of the camera: that the head of the tripod was so well engineered that the camera stayed balanced where you had left it, which is not necessarily true of some modern cameras; and the ability to pre-set shots, allowing for fast, accurate shot changes during a recording. The limitations from the cameraman's perspective were also insightful: the inability to tilt the viewfinder, causing awkward operating positions; the inability to focus on close objects; and the length of the camera body and lens, meaning a pan resulted in a sweeping arc of the lens. You need someone of Malcolm's experience to add meaning to the equipment. It is the combination of man and machine, which provides us with a compelling living history. The man has memory stimulated by re-operating the machine and the machine comes alive to do its job, under his operation. It is this combination, which reveals the hidden histories of television professions.

The EMI 2001 camera was a favourite amongst camera operators of the 1970s and '80s, although not necessarily amongst engineering managers. ${ }^{20}$ Cameramen liked the manoeuvrability of the camera, due to the lens being enclosed within the body of the camera, meaning that the pivot point of the camera was far closer to the operator, giving a more intimate feel to shots. As Malcolm demonstrates, you could cut between pre-set shots whilst changing focus with the same hand at the same time, and the viewfinder was tiltable. This improved functionality over the Pye PC80, made the EMI 2001 easier to operate and achieve good results with. Without a skilled operator explaining the differences between the two cameras, it would be hard to appreciate the significance of the improvements.

An incidental comment from Malcolm about the use of drive-in scanners tells us much about the pressure on the BBC to create colour content in the late 1960s and early ' 70 s, despite the Corporation not being able to update its studio infrastructure quickly. From the time the CMCR scanners were built in 1969 they were routinely used as a pragmatic solution for creating colour programming in black and white studios. The scanner would drive as close to the studio as possible and cable its colour cameras into the studio, using it as a lit set, rather than as a fully operative studio. This practice happened at the BBC Birmingham studio in Gosta Green, before the purpose built, colour facilities were completed at Pebble Mill in 1971, ${ }^{21}$ and according to Malcolm, the same was happening in Manchester in the early 1970s. Without this kind of video interview, production practices such as this might not come to light.

Scanners like CMCR9 were fitted with 2-inch videotape (VT) recorders, and then later with 1-inch VT recorders, as the technology improved. The VT machines enabled the output from the vision mixer to be recorded, as not all outside broadcasts were live, for example, Gardeners' World. There were usually two VT machines on a truck. At the moment

20 Discussion from a lighting director, engineer and cameraman about the EMI 2001 camera, 2011, http://www.pebblemill.org/blog/mortedarthur-david-short-cameraman/

${ }^{21}$ John Duckmanton, 'CMCR6 Birmingham's first colour scanner,' http://www.pebblemill.org/blog/cmcr6-birminghams-first-colour-scanner/ 
there are no VT machines on the restored CMCR9, although in the longer term the restoration team would like to put one back in.

\subsection{Early Slow Motion and Why Taped Analogue Programmes Were Recorded Over}

In the third interview there were two discoveries for me, firstly, how slow motion shots were created by physically spooling the tape, and secondly, why so many taped analogue programmes were recorded over and never archived.

In January 2013 BBC Birmingham's post-production department was being closed down, as factual network production programmes, including Countryfile, Gardners' World and Coast (2005-present), were being relocated to BBC Bristol. A 1-inch VT machine had been kept by post-production in case 1-inch archive material ever needed transferring to modern formats. Before the machine was disposed of and the editors were made redundant, I took the opportunity of asking one of the VT engineers, John Duckmanton, to demonstrate the 1-inch machine to me. The machine was a little temperamental, and took a while to get working, but the resulting video interview includes some interesting insights into the functionality of the machine, and the improvements it had over the original 2-inch VT machines.

One of the most surprising pieces of information resulting from this video is the technique of creating slow motion shots for use in sports coverage. Before I recorded this interview, I had not thought about how slow motion shots were achieved in this era. The fact that the slow motion was achieved by the VT operator manually spooling the tape and adjusting the speed accordingly, seems incredibly crude and haphazard as a method. It is little wonder that mistakes were made, as it was so easy to spool beyond a shot change and ruin the effect.

The complexity of linear analogue tape editing, compared to modern non-linear systems is clear from this video interview. We also get an insight into the results of economics on production practices, and the impact this had on archiving. The fact that 2-inch videotape was extremely expensive led to tapes being bulk erased and re-used. This practice goes someway to explain the paucity of studio and outside broadcast programme archives from the 1970s.

All these videos are openly accessible on both the Vimeo platform and on the Pebble Mill website.

\section{Wider Relevance and Reproducibility}

In each of these video interview examples we learn about the practices behind hidden television professions and gain some understanding of the complexity of programme making in the analogue age. However, I would argue that we gain something wider as well, something about the culture of production: for instance, about the reliance on the general post office telephone infrastructure for early outside broadcast transmission; about how the BBC created colour programming despite the limitations of its black and white studios; and about why so many taped analogue programmes from the 1970s were never archived and consequently do not survive. These are incidental to the main purpose of the interviews, but arguably of even more significance to the television historian.

Reuniting skilled technicians with the equipment they habitually operated seems to provide a rich opportunity for effective reminiscence and re-creation. Memory is stimulated by the physical presence of the machinery, in a way that would be difficult to imagine without it. Despite the logistical difficulties in achieving these encounters, I would suggest that they are worth the effort of engineering, as the results are often illuminating and surprising. It would seem 
that these films, and indeed the wider Pebble Mill project provide a model that could be successfully adopted in other historical projects, and which have significance for television historians outside of the United Kingdom.

Oral history projects usually rely on audio recordings, but given the visual nature of the subject matter with this project, video recording may provide a more satisfactory result, despite the necessity of additional equipment and an interviewer/practitioner with video shooting and editing skills. It would seem sensible that other visual projects consider adopting similar models. Not only does the video interview seem to be the most suitable method of recording these histories, but certainly the most engaging way of disseminating them widely online.

\section{Biography}

Vanessa Jackson is a former BBC series producer, and now course director of the BA in Media and Communication, and degree leader of Television at Birmingham City University, teaching practical television production skills to undergraduates. She is studying, part-time, for a practice based $\mathrm{PhD}$ at Royal Holloway, in television historiography, under the supervision of Professor John Ellis. Her research interests include the history of television, as well as the uses of social media in community history projects. She has also published on the use of social media in enhancing student employability, and on student engagement. 